\title{
Supportive Care in AL Amyloidosis
}

\author{
M. Teresa Cibeira ${ }^{a} \quad$ José T. Ortiz-Pérez ${ }^{b}$ Luis F. Quintana ${ }^{c}$ \\ Carlos Fernádez de Larrea ${ }^{\mathrm{a}}$ Natalia Tovar ${ }^{\mathrm{a}}$ Joan Bladéa
}

${ }^{a}$ Hematology Department, Amyloidosis and Myeloma Unit, Hospital Clínic of Barcelona, University of Barcelona, IDIBAPS, Barcelona, Spain; ${ }^{b}$ Cardiology Department, Amyloidosis and Myeloma Unit, Hospital Clínic of Barcelona,

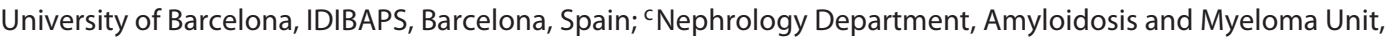
Complex Glomerular Disease Unit (CSUR), Hospital Clínic of Barcelona, University of Barcelona, IDIBAPS,

Barcelona, Spain

\section{Keywords}

AL amyloidosis · Cardiac amyloidosis · Nephrotic syndrome · Supportive care $\cdot$ Treatment

\begin{abstract}
Immunoglobulin light-chain ( $\mathrm{AL}$ ) amyloidosis is a systemic disease characterized by the production and deposition of light chain-derived amyloid fibrils in different organs. Prompt treatment directed to the underlying plasma cell clone is crucial in order to achieve a rapid, deep and durable hematologic response. The decrease in the production of the amyloidogenic light chains is a required condition to obtain the organ response, which is commonly delayed. Meanwhile, supportive treatment is aimed to maintain quality of life of these patients and preserve their involved organs' function. From simple measures, such as salt restriction or compressive stockings, to very complex interventions, such as heart transplantation in very selected patients with isolated severe cardiac involvement, this supportive care is essential and has to be necessarily included in the multidisciplinary management of this disease.

(c) 2020 S. Karger AG, Base
\end{abstract}

(C) 2020 S. Karger AG, Basel

www.karger.com/aha

Karger ${ }^{\prime}=$

\section{Introduction}

Immunoglobulin light chain $(\mathrm{AL})$ amyloidosis is a plasma cell disorder characterized by the production of monoclonal light chains, more frequently of lambda type, prone to misfold resulting in amyloid aggregates [1]. Organ damage is produced by organ deposition of these amyloid aggregates and also by direct cytotoxicity of circulating amyloidogenic precursors [2]. The heart and the kidneys are the most frequently involved organs, but $\mathrm{AL}$ amyloidosis is a systemic disease that can affect any organ, with the exception of central nervous system. In fact, every patient has its own organ involvement, usually the same throughout his or her disease history, probably depending on patient's type of light chain and yet unknown factors that define the interaction between amyloid and target tissues [3-7]. This makes AL amyloidosis a very heterogeneous disease regarding organ involvement and clinical manifestations, conditioning patient's quality of life and the potential toxicity of treatment. Thus, a riskadapted therapeutic approach is critical [8], taking into account the two most important prognostic factors: cardiac involvement and tumor burden, both reflected in the revised staging system stablished in 2012 [9]. In this re-

M. Teresa Cibeira

Hematology Department, Amyloidosis and Myeloma Unit / Hospital Clínic of Barcelona Villarroel Street, n. 170 ES-08030 Barcelona (Spain) MCIBEIRA@ clinic.cat 
gard, the main available treatment options are oral or intravenous alkylating agents, including high-dose melphalan followed by stem cell transplant (HDM/SCT), proteasome inhibitors, immunomodulatory drugs and the anti-CD38 monoclonal antibody daratumumab. All these therapies pursue to suppress the production of amyloidogenic light chains (hematologic response) in order to avoid further progression of organ damage and, hopefully, allow the recovery of organ function (organ response). With this objective, a rapid, deep and durable reduction of the plasma cell burden is crucial, but it is equally important to target the organ damage itself through supportive measures that are the objective of this review. Fibril-directed therapies are also under development and hopefully will be of major help in the near future but are not on the scope of this article [10].

\section{Supportive Care for Renal AL Amyloidosis}

The kidney is the most frequently involved organ in AL amyloidosis (70-80\% of patients) [11]. Renal deposition of amyloid fibrils is predominantly glomerular and presents as proteinuria that can evolve to nephrotic syndrome in around one third to one half of patients. These cases typically present with a marked increase in plasma levels of cholesterol, low-density lipoprotein, triglycerides and lipoprotein(a), which usually show resistance to hypolipidemic drugs, as well as peripheral edema in the context of severe hypoalbuminemia. In contrast, the presentation with progressive renal failure is less frequent, with only around $20 \%$ of patients showing a serum creatinine level higher than $2 \mathrm{mg} / \mathrm{dL}$.

Treatment of this condition is based on diuretics (mainly loop diuretics) as well as strict fluid and salt restriction to reduce symptomatic edema and fluid overload. In patients with severe hypoalbuminemia, concomitant administration of albumin might be more efficient than diuretics alone. Angiotensin-converting enzyme (ACE) inhibitors and angiotensin-receptor blockers (ARBs) are frequently used to minimize proteinuria, similarly as they are used in the management of diabetic nephropathy, although there is no evidence supporting its use in amyloidosis [12]. However, renin-angiotensin system blockers should be avoided in patients with significant cardiac or autonomic nervous system involvement, particularly in the presence of hypotension. In patients with very low serum albumin levels (particularly below 20 $\mathrm{g} / \mathrm{L}$ ), indication of prophylactic anticoagulation should be considered while taking into account the potential bleed- ing risk associated with this disease [13]. Control of blood pressure and serum cholesterol should not be unattended.

It must be pointed out that glomerular proteinuria is one of the most responsive AL manifestations to effective anti-plasma cell therapy which, at the end, is the most important treatment aiming at improving renal function [14]. In our experience and once achieved a good quality hematologic response, renal response can appear at any time from 3 to 18 months after onset of effective treatment. During this time period, the objective of supportive therapy is to preserve renal function. As previously stated, serum creatinine is normal at diagnosis in the majority of patients but can easily worsen as a result of excessive depletion, hypotension, infections or the use of nephrotoxic agents including contrast media, all of them factors that should be avoided. Progression to end-stage renal disease occurs in a variable proportion of patients ranging from 15 to $31 \%$ according to different series $[15,16]$. Renal staging system allows a better estimation of renal outcomes based on baseline proteinuria and estimated glomerular filtration rate, using thresholds of $5 \mathrm{~g} / 24 \mathrm{~h}$ and $50 \mathrm{~mL} / \mathrm{min}$, respectively [16]. Decisions regarding renal replacement therapy should take into consideration different factors such as age, severity of extrarenal organ involvement and availability of effective anti-plasma cell rescue therapy. Survival following the start of dialysis due to renal amyloidosis is shorter than in other renal diseases, mainly due to the frequently associated cardiac amyloid involvement [15]. In those patients with coexisting cardiac or autonomic involvement, hemodialysis can be limited by hypotension. This situation may be alleviated with administration of midodrine before dialysis. No differences have been observed between hemodialysis and peritoneal dialysis [17].

Finally, renal transplantation can be considered in selected cases. Four small series of patients with AL amyloidosis who received a kidney transplant before or after high-dose melphalan and stem cell rescue have suggested a benefit both in terms of dialysis-free survival and overall survival [18-21]. The benefit was observed particularly in those patients without cardiac involvement who achieved a complete hematologic response after chemotherapy. Although recurrence of amyloidosis can occur in the transplanted kidney, availability of more effective anti-plasma cell therapies can help to overcome this situation. Moreover, avidity of amyloid fibrils for the transplanted organ could be different than previous tropism for the native kidney. Coexistence of renal AL amyloidosis with cardiac involvement can complicate the clinical features and their therapeutic management. 


\section{Supportive Care for Cardiac AL Amyloidosis}

The second most frequently involved organ is the heart, although the frequency is always dependent on the sensitivity of the diagnostic tests [22]. Around $50-60 \%$ of patients with $\mathrm{AL}$ amyloidosis were considered to have heart involvement by means of echocardiography [11], while a higher frequency has been reported thanks to the introduction of more sensitive studies such as cardiac magnetic resonance imaging or serum cardiac biomarkers, including troponin I or T and brain natriuretic peptide (BNP) or its N-terminal pro-peptide NT-proBNP. Patients with heart involvement usually present with heart failure (around 15-20\% of them at diagnosis) or ventricular arrhythmias than can lead to recurrent syncope or cardiac arrest. Onset of symptoms can be abrupt and have a rapidly progressing clinical picture. Low voltages are frequently observed by electrocardiography, but it can also show a pseudo-infarct pattern as well as atrioventricular or intraventricular conduction abnormalities. Echocardiography typically reveals non-dilated ventricles with concentric hypertrophy, usually with interventricular septum thickness over $12 \mathrm{~mm}$ and diastolic function parameters ranging from increased filling pressures to restrictive filling pattern. It is important to acknowledge that both circumferential and radial shortening of the myocardium is fairly preserved until advanced stages of the disease, giving the false impression that the ejection fraction is preserved. Therefore, in the presence of a high clinical suspicion of cardiac involvement, appropriate and directed evaluation of longitudinal shortening of the ventricles with advanced functional techniques, such as tissue Doppler or strain rate imaging, can be very helpful. Prognosis in AL amyloidosis depends mostly on the presence and severity of cardiac involvement, as reflected by the role of cardiac biomarkers in the first cardiac staging system [23] and the subsequent revised prognostic model also including serum free light chains [9]. In the last decade, the introduction of new therapeutic agents has allowed to improve survival in this population. Along with the improved survival, special considerations in the supportive care have to be taken in mind.

The mainstay of symptomatic cardiac failure in $\mathrm{AL}$ myocardiopathy is based on diuretics, particularly the combination of loop diuretics (furosemide or torasemide) and aldosterone receptor blockers (mainly spironolactone) [24]. Their doses are limited by the risk of symptomatic hypotension in patients with autonomic neuropathy or worsening of renal function in those with renal amyloid disease. It is recommended that close mon-

Supportive Care in AL Amyloidosis itoring of tolerance, renal function and serum ions should be conducted in the initial phases of treatment. In selected cases, other diuretics such as chlortalidone, metolazone, acetazolamide or thiazides may be useful. In refractory patients, different diuretic combinations or periodic thoracocentesis may be considered [25]. On the contrary, beta blockers and ACE inhibitors or ARBs, considered standard treatment for heart failure with reduced ejection fraction, cannot be recommended routinely in this disease and are often poorly tolerated. Sinus tachycardia is necessary to maintain an adequate cardiac output in $\mathrm{AL}$ amyloidosis and beta blockers might suppress this physiological compensatory mechanism, in addition to their negative inotropic and chronotropic effect, leading to decompensated heart failure. Also, patients with cardiac amyloidosis depend on angiotensin for maintenance of blood pressure, so that the use of ACE inhibitors or ARBs can induce severe hypotension [26]. Similarly, calcium channel blockers are contraindicated due to their negative inotropic effects [27].

Rhythm abnormalities can arise in cardiac AL amyloidosis, many of which are life-threatening in nature. Amyloid deposition in the myocardium and the conduction system is an excellent substrate for arrhythmia generation. Ventricular tachycardia, ventricular fibrillation and pulseless electrical activity are common in advanced stages of the disease $[28,29]$, the latest found to be the most frequent cause of sudden death in a study of implanted cardiac rhythm recorders [30]. Cardiac rate control is difficult even in patients who develop atrial fibrillation or flutter. High avidity of digoxin for amyloid has been described, which might result in binding of the drug to deposited fibrils and, consequently, increased intracardiac drug concentrations with the risk of life-threatening arrhythmias [31]. As previously stated, beta blockers are often poorly tolerated mainly due to hypotension, but low doses may be beneficial in selected patients. Non-dihydropyridine calcium channel blockers can cause bradycardia and have negative inotropic effects [27]. In this setting, the best tolerated option for rhythm control is amiodarone, also recommended by some authors for primary arrythmia prophylaxis at a dose of $200 \mathrm{mg}$ /day in patients with high-risk features on Holter monitor testing such as ventricular couplets or non-sustained ventricular tachycardia [32]. However, there is no evidence based on controlled clinical trials supporting the use of prophylactic antiarrhythmic drugs [33]. Catheter ablation is not recommended as a first choice in supraventricular or ventricular arrhythmias due to the frequent multifocal nature and the high recurrence rate [34]. Atrial or atrioventricu- 
lar nodal ablation with permanent pacemakers can be considered for selected patients [25]. The role of implantable cardioverter-defibrillator therapy remain controversial given that no survival benefit has been demonstrated to date, the lack of randomized studies and futility in patients with very poor prognosis, in addition to the fact that pulseless electrical activity is one of the most common preterminal events [25, 28, 34, 35].

Intracardiac thrombi are another possible complication in AL amyloidosis despite sinus rhythm [36]. Atrial thrombus, mainly located in the right or left atrial appendages, was found by transesophageal echocardiography in $35 \%$ of patients with this disease [37]. The incidence of thromboembolism is higher in patients with atrial fibrillation in the presence of cardiac AL amyloidosis than in other more common forms of atrial fibrillation [38]. Therefore, anticoagulation has to be considered in an individualized basis counterbalancing the higher hemorrhagic risk of this population due to the potential association of vascular amyloid deposition, factor X deficiency and liver involvement. As a general recommendation, anticoagulation should be given for any atrial arrhythmia and in patients with sinus rhythm whose echocardiography shows features of left atrial mechanical dysfunction [39].

Finally, heart transplantation should be considered for highly selected patients. In the Mayo Clinic experience, only 23 among more than 3,000 patients with AL amyloidosis seen over a 20 -year period underwent this procedure [40]. A number of small case series have been published to date. Outcomes were very discouraging in the first patients transplanted upfront and followed by nonintensive chemotherapy [41]. With the introduction of HDM/SCT performed closely after heart transplantation, outcomes became similar to those obtained in patients transplanted for non-amyloid cardiomyopathies [18, 40, 42-44], which turned cardiac amyloidosis into an acceptable indication for heart transplantation, according to the 2016 Listing Criteria of the International Society for Heart and Lung Transplantation [45]. Patients who might benefit more from this approach would be those being younger and with isolated cardiac involvement. Now that more effective and less toxic anti-plasma cell agents are available, it is recommended that the heart transplant be preceded by an induction regimen with the aim to reduce the circulating amyloidogenic light chain burden and avoid disease progression leading to the high mortality observed while in the waiting list [44]. This induction regimen would preferably be bortezomib-based, given the rapid responses attributed to this agent, and dose-adjust- ed in order to minimize toxicity. In some of these patients, high-quality hematologic responses could translate into a clinical improvement of heart failure, although rarely enough to avoid heart transplantation. This procedure should also be followed by an HDM/SCT within 3-6 months in order to obtain the best possible hematologic response and avoid amyloid deposition in the transplanted heart. With this sequential approach, an overall survival up to $90 \%$ at 1 year and $60 \%$ at 5 years has been reported $[40,44]$. In case of progression of the underlying plasma cell dyscrasia, the use of immunomodulatory drugs as rescue therapy has been associated with a potential risk of organ rejection [46].

\section{Supportive Care for AL Neuropathy}

Around $20 \%$ of patients diagnosed with AL amyloidosis develop peripheral neuropathy. It usually consists in numbness and paresthesia affecting more frequently the lower limbs, symmetric and progressive, sometimes painful, and with less frequently associated motor impairment. These symptoms rarely improve despite good quality hematologic response after chemotherapy. In this context, supportive care is very important mainly in order to alleviate discomfort from neuropathic pain [47]. Treatment is based on studies performed in patients with diabetic and other forms of neuropathy. Drugs frequently used are anticonvulsants (gabapentin and pregabalin) and serotonin-norepinephrine reuptake inhibitors (duloxetine and venlafaxine). Tricyclic antidepressants such as amitriptyline and nortriptyline are usually not used because they can impair concurrent autonomic symptoms. Some authors recommend the use of topical preparations based on lidocaine, ketamine or capsaicin.

Another $15 \%$ of patients complain of symptoms associated with autonomic neuropathy that are difficult to manage. In those with symptomatic orthostatic hypotension, which can be only exertional-associated or severe enough to prevent from just walking or even standing up, different supportive measures have been suggested. Wearing compression stockings (either thigh or waist high) can help in some instances by facilitating venous return, also reducing peripheral edema. The alpha-adrenergic agonist midodrine can be administered orally at an initial dose of $2.5 \mathrm{mg}$ t.i.d. and progressively increased to a maximum dose of $10 \mathrm{mg}$ t.i.d., taking care of potential adverse events such as supine hypertension and tachycardia [32]. In uncommon cases without concomitant nephrotic syndrome or amyloid cardiomyopathy, fludro- 
cortisone (100-200 $\mu \mathrm{g} /$ day) or salt tablets can be used taking care to avoid supine hypertension. Newer agents such as pyridostigmine and droxidopa could also be considered in selected cases [48]. At the end, if we are not able to improve patient's manifestations, at least we should try not to worsen them with over-diuresis and fluid depletion. Other manifestations of dysautonomy are impotence, bladder or bowel dysfunction, the latest discussed in the following section.

\section{Supportive Care for Gastrointestinal AL Amyloidosis}

Gastrointestinal symptoms may appear as a result of autonomic neuropathy or, less frequently, amyloid deposition that can be associated with weight loss, malabsorption or gastrointestinal bleeding. Autonomic dysfunction can cause postprandial fullness due to gastroparesis and motility disturbance, including constipation or diarrhea. In patients with gastroparesis, metoclopramide can improve the gastric emptying, while diarrhea can be managed by adding fiber to the diet to increase stool bulk or using anti-motility agents (loperamide), bile acid binders or subcutaneous octreotide in refractory patients $[24,49,50]$. However, supportive care cannot be limited to the use of these drugs plus the suggestion of some dietary modifications. Since these symptoms can not only greatly impair patients' quality of life but are also strongly associated with a limited tolerance to chemotherapy, prompt and appropriate nutritional support is mandatory. This support should be conducted by professionals with specific skills and training (dietitians and clinical nutritionists), including artificial nutrition and, if required, central parental nutrition. In selected cases with severe gastrointestinal hemorrhage or bowel obstruction, surgical resection may be required [51].

Liver involvement is present in around one fourth of the patients. Main clinical features are palpable hepatomegaly and increased serum alkaline phosphatase. A small proportion of patients (around 2\%) present with cholestatic jaundice that is associated with very poor prognosis (median survival of less than 1 month if serum bilirubin is over $2 \mathrm{mg} / \mathrm{dL}$ ) [52]. Splenomegaly is rare (5\%) but spontaneous rupture of the spleen with hypovolemic shock has been reported as initial manifestation of the disease [53] and one fourth of patients have hyposplenism with the presence of Howell-Jolly bodies in peripheral blood smears [11]. Antipneumococcal vaccination should be recommended in these cases.

Supportive Care in AL Amyloidosis

\section{Supportive Care for Pulmonary AL Amyloidosis}

Amyloidosis involving the lungs can appear both in the context of localized and systemic AL amyloidosis. Differential diagnosis between both types is crucial since the treatment approach is completely different, and chemotherapy is only indicated in systemic disease. Patients with systemic AL amyloidosis and lung involvement can present different patterns such as diffuse (interstitial or alveolar-septal), nodular, pleural disease and rarely diaphragm deposition. Supportive care is of special interest in patients with symptomatic pleural effusions and consists of optimizing cardiac filling pressures, performing serial drainage of pleural fluid in order to achieve symptomatic relief and, in selected cases, consider pleurodesis to decrease recurrences $[54,55]$.

Patients with localized pulmonary amyloidosis usually display a nodular pattern, with few or no symptoms, or a tracheo-bronchial disease, with moderate to severe symptoms requiring local therapy. Therefore, management of tracheo-bronchial localized AL amyloidosis depends on the presence and severity of symptoms, treatment options including laser excision [56] and low-dose external beam radiation [57]. It should be noted that repeated diagnostic or therapeutic rigid bronchoscopies or laser treatments can result in scar stenosis and worsen the manifestations of the disease. Oral agents such as colchicine, glucocorticoids, and iodinated isoform of doxorubicin (IDOX) have been used with poor results, while systemic chemotherapy is not indicated. Finally, supportive care includes mucolytic agents to avoid mucous production that can further reduce airway lumen, prophylactic antimicrobial agents, regular nebulizer use and courses of oral or inhaled glucocorticoids [54].

\section{Supportive Care for Other AL Manifestations}

Other typical symptoms in AL amyloidosis are derived from amyloid deposition in soft tissues. Median nerve compression due to carpal tunnel syndrome can be treated with specific braces or, if severe, surgically with carpal tunnel release [11]. Dry mouth due to involvement of salivary glands may also be one of the initial symptoms and can be improved with some dietary recommendations. Despite lack of clinical evidence in AL amyloidosis, the authors of this review consider that clinical practice guidelines for oral management in Sjögren's syndrome including application of topical fluoride to prevent tooth decay and, in refractory cases, the addition

Acta Haematol 2020;143:335-342 
of remineralizing agents, chlorhexidine antimicrobial rinses and stimulation of saliva with sugar free lozenges or oral secretagogues such as pilocarpine, could be considered [58].

Progressive enlargement of the tongue (macroglossia) appears in $10-15 \%$ of patients, often associated with enlargement of submandibular structures. It can cause hypo- and oropharyngeal blockage resulting in dysphagia, speech impairment and potential upper airway obstruction, and can also limit the tolerability to anti-plasma cell therapy. Moreover, despite achievement of a good quality hematologic response, macroglossia usually shows little or no improvement. In this context, steroid therapy is the only measure that temporarily improves symptoms caused by macroglossia (author's observation), while external beam radiation therapy is not recommended due to lack of benefit [59]. Anecdotical reports describe tongue debulking with partial glossectomy via a pull-through approach as another treatment option to be considered in very selected patients with severe macroglossia in the context of otherwise controlled systemic disease (without significant involvement of vital organs and stable hematologic response). However, the role of surgery is controversial and should be very carefully considered due to the increased risk of bleeding, suturing complications, postoperative sequelae and possibility of relapse $[60,61]$.

In patients with acquired factor $\mathrm{X}$ deficiency associated with AL amyloidosis (around 15\% of cases), supportive treatment with activated recombinant factor VII might be considered in those undergoing invasive procedures, particularly if it is a severe deficiency and in case of vascular interventions such as insertion of a central venous catheter [62, 63].

Finally, amyloid can rarely involve the joints, periarticular structures and bones. Amyloid arthropathy has been reported to occur in $3.7 \%$ of patients with $\mathrm{AL}$ amyloidosis, usually presenting as a nonerosive symmetric polyarthritis due to amyloid deposition in the synovial membranes resulting in periarticular thickening associated with pain and stiffness. The most frequently affected joints are the shoulders, followed by interphalangeal joints, hips, knees, wrists and elbows [4]. In a systematic analysis of 101 reported cases of amyloid arthropathy associated with multiple myeloma, it was suggested that symptoms improved with treatments targeting arthritis, such as nonsteroidal anti-inflammatory drugs, intra-articular corticosteroid injections (in case of mono- or oligoarthritis) or even radiosynovectomy [64]. Very rarely, amyloid can form tumors named amyloidomas that can be located next to the joints, in the bone (producing lytic lesions or pathologic fractures), in soft tissues or even presenting as mediastinal or retroperitoneal tumors. Amyloidoma excision can be individually considered in symptomatic patients.

\section{Conclusion}

A supportive comprehensive care is essential in the treatment approach of patients with AL amyloidosis. It should go hand in hand with anti-plasma cell therapy, with the common objective of preserving organ function, relieving symptoms and improving patients' quality of life. These supportive measures should be established as soon as diagnosis is done, adjusted during administration of chemotherapy and subsequently, while waiting for the hematologic response that will hopefully result in amyloid-involved organ improvement. With this purpose and given the systemic nature of this disease, a multidisciplinary approach is mandatory. Thus, treatment of patients should be conducted in experienced multidisciplinary amyloid centers, with the needed and critical involvement of different specialists with expertise in the management of this complex and heterogeneous disease.

\section{Acknowledgement}

This work has been supported in part by grants from the Instituto de Salud Carlos III (Spanish Ministry of Health) PI19/00669, FIS PI15/00531 and FIS PI17/00080, Fondo Europeo de Desarrollo Regional (FEDER), Fundació Marato TV3 2015303132 and 2017SGR00792 from Agència de Gestió d'Ajuts Universitaris i de Recerca (AGAUR, Generalitat de Catalunya).

\section{Disclosure Statement}

M.T.C. received honoraria for educational lectures from Janssen, Celgene and Amgen, and from advisory boards from Janssen and Akcea. J.T.O.-P. received honoraria for educational lectures from General Electric, Medical Dosplus SL, Aztrazeneca, Bristol Myers Squibb-Pfizer, Psyma Iberica Marketing Research and from Akcea for advisory boards. L.F.Q. received honoraria for educational lectures from Akcea, Celgene and Amgen. C.F.L. received honoraria for educational lectures from Janssen, Celgene and Amgen, advisory boards from Janssen, Celgene, Amgen and Takeda, and research grants from Celgene, Amgen, Takeda, and Janssen. N.T. received honoraria for educational lectures from Janssen. J.B. received honoraria for educational lectures and advisory boards from Janssen, Celgene, Amgen and Takeda. 
Funding Sources

None.

\section{References}

1 Merlini G, Bellotti V. Molecular mechanisms of amyloidosis. N Engl J Med. 2003 Aug; 349(6):583-96.

2 Sikkink LA, Ramirez-Alvarado M. Cytotoxicity of amyloidogenic immunoglobulin light chains in cell culture. Cell Death Dis. 2010 Nov;1(11):e98.

3 Comenzo RL, Wally J, Kica G, Murray J, Ericsson T, Skinner M, et al. Clonal immunoglobulin light chain variable region germline gene use in AL amyloidosis: association with dominant amyloid-related organ involvement and survival after stem cell transplantation. Br J Haematol. 1999 Sep;106(3): 744-51.

4 Prokaeva T, Spencer B, Kaut M, Ozonoff A, Doros G, Connors LH, et al. Soft tissue, joint, and bone manifestations of AL amyloidosis: clinical presentation, molecular features, and survival. Arthritis Rheum. 2007 Nov;56(11): 3858-68.

5 Perfetti V, Palladini G, Casarini S, Navazza V, Rognoni $\mathrm{P}$, Obici $\mathrm{L}$, et al. The repertoire of $\lambda$ light chains causing predominant amyloid heart involvement and identification of a preferentially involved germline gene, IGLV1-44. Blood. 2012 Jan;119(1):144-50.

6 Milani P, Merlini G. Monoclonal IgM-related AL amyloidosis. Best Pract Res Clin Haematol. 2016;29(2):241-8.

7 Sidiqi MH, Aljama MA, Muchtar E, Buadi FK, Warsame R, Lacy MQ, et al. Light chain type predicts organ involvement and survival in $\mathrm{AL}$ amyloidosis patients receiving stem cell transplantation. Blood Adv. 2018 Apr;2(7): 769-76.

8 Dispenzieri A, Buadi F, Kumar SK, Reeder CB, Sher T, Lacy MQ, et al. Treatment of Immunoglobulin Light Chain Amyloidosis: Mayo Stratification of Myeloma and RiskAdapted Therapy (mSMART) Consensus Statement. Mayo Clin Proc. 2015 Aug;90(8): 1054-81.

9 Kumar S, Dispenzieri A, Lacy MQ, Hayman SR, Buadi FK, Colby C, et al. Revised prognostic staging system for light chain amyloidosis incorporating cardiac biomarkers and serum free light chain measurements. J Clin Oncol. 2012 Mar;30(9):989-95.

10 Bhutani D, Leng S, Lentzsch S. Fibril-directed Therapies in Systemic Light Chain AL Amyloidosis. Clin Lymphoma Myeloma Leuk. 2019 Sep;19(9):555-9.

11 Kyle RA, Gertz MA. Primary systemic amyloidosis: clinical and laboratory features in 474 cases. Semin Hematol. 1995 Jan;32(1): $45-59$.

\section{Author Contributions}

M.T.C. and J.B. wrote the manuscript; J.T.O.-P., L.F.Q., C.F.L. and N.T. reviewed the draft manuscript, made suggestions and modifications. All authors approved the final version for submission.
12 Gentile G, Remuzzi G, Ruggenenti P. Dual renin-angiotensin system blockade for nephroprotection: still under scrutiny. Nephron. 2015;129(1):39-41.

13 Lee T, Biddle AK, Lionaki S, Derebail VK, Barbour SJ, Tannous S, et al. Personalized prophylactic anticoagulation decision analysis in patients with membranous nephropathy. Kidney Int. 2014 Jun;85(6):1412-20.

14 Pinney JH, Lachmann HJ, Bansi L, Wechalekar AD, Gilbertson JA, Rowczenio D, et al. Outcome in renal $\mathrm{Al}$ amyloidosis after chemotherapy. J Clin Oncol. 2011 Feb;29(6): 674-81.

15 Gertz MA, Kyle RA, O’Fallon WM. Dialysis support of patients with primary systemic amyloidosis. A study of 211 patients. Arch Intern Med. 1992 Nov;152(11):2245-50.

16 Palladini G, Hegenbart U, Milani P, Kimmich C, Foli A, Ho AD, et al. A staging system for renal outcome and early markers of renal response to chemotherapy in $\mathrm{AL}$ amyloidosis. Blood. 2014 Oct;124(15):2325-32.

17 Moroni G, Banfi G, Montoli A, Bucci A, Bertani T, Ravelli M, et al. Chronic dialysis in patients with systemic amyloidosis: the experience in northern Italy. Clin Nephrol. 1992 Aug;38(2):81-5.

18 Sattianayagam PT, Gibbs SD, Pinney JH, Wechalekar AD, Lachmann HJ, Whelan CJ, et al. Solid organ transplantation in AL amyloidosis. Am J Transplant. 2010 Sep;10(9): 2124-31.

19 Herrmann SM, Gertz MA, Stegall MD, Dispenzieri A, Cosio FC, Kumar S, et al. Longterm outcomes of patients with light chain amyloidosis (AL) after renal transplantation with or without stem cell transplantation. Nephrol Dial Transplant. 2011 Jun;26(6): 2032-6.

20 Angel-Korman A, Stern L, Sarosiek S, Sloan JM, Doros G, Sanchorawala V, et al. Longterm outcome of kidney transplantation in AL amyloidosis. Kidney Int. 2019 Feb;95(2): 405-11.

21 Sathick IJ, Rosenbaum CA, Gutgarts V, Landau H. Kidney transplantation in AL Amyloidosis: is it time to maximize access? Br J Haematol. 2020 Feb;188(3):e1-4.

22 Aljama MA, Sidiqi MH, Dispenzieri A, Gertz MA, Lacy MQ, Buadi FK, et al. Comparison of different techniques to identify cardiac involvement in immunoglobulin light chain (AL) amyloidosis. Blood Adv. 2019 Apr;3(8): 1226-9.

23 Dispenzieri A, Gertz MA, Kyle RA, Lacy MQ, Burritt MF, Therneau TM, et al. Serum car- diac troponins and N-terminal pro-brain natriuretic peptide: a staging system for primary systemic amyloidosis. J Clin Oncol. 2004 Sep; 22(18):3751-7.

24 Gertz MA, Lacy MQ, Dispenzieri A. Therapy for immunoglobulin light chain amyloidosis: the new and the old. Blood Rev. 2004 Mar; 18(1):17-37.

25 Dispenzieri A, Merlini G. Immunoglobulin light chain systemic amyloidosis. Cancer Treat Res. 2016;169:273-318.

26 Kapoor P, Thenappan T, Singh E, Kumar S, Greipp PR. Cardiac amyloidosis: a practical approach to diagnosis and management. Am J Med. 2011 Nov;124(11):1006-15.

27 Gertz MA, Falk RH, Skinner M, Cohen AS, Kyle RA. Worsening of congestive heart failure in amyloid heart disease treated by calcium channel-blocking agents. Am J Cardiol. 1985 Jun;55(13 Pt 1):1645.

28 Palladini G, Malamani G, Cò F, Pistorio A, Recusani F, Anesi E, et al. Holter monitoring in $\mathrm{AL}$ amyloidosis: prognostic implications. Pacing Clin Electrophysiol. 2001 Aug;24(8 Pt 1):1228-33.

29 Kristen AV, Dengler TJ, Hegenbart U, Schonland SO, Goldschmidt H, Sack FU, et al. Prophylactic implantation of cardioverter-defibrillator in patients with severe cardiac amyloidosis and high risk for sudden cardiac death. Heart Rhythm. 2008 Feb;5(2):235-40.

30 Sayed RH, Rogers D, Khan F, Wechalekar AD, Lachmann HJ, Fontana M, et al. A study of implanted cardiac rhythm recorders in advanced cardiac AL amyloidosis. Eur Heart J. 2015 May;36(18):1098-105.

31 Rubinow A, Skinner M, Cohen AS. Digoxin sensitivity in amyloid cardiomyopathy. Circulation. 1981 Jun;63(6):1285-8.

32 Weber N, Mollee P, Augustson B, Brown R, Catley L, Gibson J, et al. Management of systemic AL amyloidosis: recommendations of the Myeloma Foundation of Australia Medical and Scientific Advisory Group. Intern Med J. 2015 Apr;45(4):371-82.

33 Barbhaiya CR, Kumar S, Baldinger SH, Michaud GF, Stevenson WG, Falk R, et al. Electrophysiologic assessment of conduction abnormalities and atrial arrhythmias associated with amyloid cardiomyopathy. Heart Rhythm. 2016 Feb;13(2):383-90.

34 Dhoble A, Khasnis A, Olomu A, Thakur R. Cardiac amyloidosis treated with an implantable cardioverter defibrillator and subcutaneous array lead system: report of a case and literature review. Clin Cardiol. 2009 Aug; 32(8):E63-5. 
35 Yaoita H, Iwai-Takano M, Ogawa K, Suzuki $\mathrm{H}$, Akutsu K, Noji H, et al. Attenuation of diastolic heart failure and life-threatening ventricular tachyarrhythmia after peripheral blood stem cell transplantation combined with cardioverter-defibrillator implantation in myeloma-associated cardiac amyloidosis. Circ J. 2008 Feb;72(2):331-4.

36 Dubrey S, Pollak A, Skinner M, Falk RH. Atrial thrombi occurring during sinus rhythm in cardiac amyloidosis: evidence for atrial electromechanical dissociation. Br Heart J. 1995 Nov;74(5):541-4.

37 Feng D, Syed IS, Martinez M, Oh JK, Jaffe AS, Grogan M, et al. Intracardiac thrombosis and anticoagulation therapy in cardiac amyloidosis. Circulation. 2009 May;119(18):2490-7.

38 Feng D, Edwards WD, Oh JK, Chandrasekaran K, Grogan M, Martinez MW, et al. Intracardiac thrombosis and embolism in patients with cardiac amyloidosis. Circulation. 2007 Nov;116(21):2420-6.

39 Falk RH, Alexander KM, Liao R, Dorbala S AL (light-chain) cardiac amyloidosis: a review of diagnosis and therapy. J Am Coll Cardiol. 2016 Sep;68(12):1323-41.

40 Grogan M, Gertz M, McCurdy A, Roeker L, Kyle R, Kushwaha S, et al. Long term outcomes of cardiac transplant for immunoglobulin light chain amyloidosis: The Mayo Clinic experience. World J Transplant. 2016 Jun; 6(2):380-8

41 Dubrey SW, Burke MM, Hawkins PN, Banner NR. Cardiac transplantation for amyloid heart disease: the United Kingdom experience. J Heart Lung Transplant. 2004 Oct; 23(10):1142-53.

42 Kristen AV, Sack FU, Schonland SO, Hegenbart U, Helmke BM, Koch A, et al. Staged heart transplantation and chemotherapy as a treatment option in patients with severe cardiac light-chain amyloidosis. Eur J Heart Fail. 2009 Oct;11(10):1014-20.

43 Dey BR, Chung SS, Spitzer TR, Zheng H, Macgillivray TE, Seldin DC, et al. Cardiac transplantation followed by dose-intensive melphalan and autologous stem-cell transplantation for light chain amyloidosis and heart failure. Transplantation. 2010 Oct; 90(8):905-11.
44 Gray Gilstrap L, Niehaus E, Malhotra R, Ton VK, Watts J, Seldin DC, et al. Predictors of survival to orthotopic heart transplant in patients with light chain amyloidosis. J Heart Lung Transplant. 2014 Feb;33(2):149-56.

45 Mehra MR, Canter CE, Hannan MM, Semigran MJ, Uber PA, Baran DA, et al.; International Society for Heart Lung Transplantation (ISHLT) Infectious Diseases, Pediatric and Heart Failure and Transplantation Councils. The 2016 International Society for Heart Lung Transplantation listing criteria for heart transplantation: A 10-year update. J Heart Lung Transplant. 2016 Jan;35(1):1-23.

46 Qualls DA, Lewis GD, Sanchorawala V, Staron A. Orthotopic heart transplant rejection in association with immunomodulatory therapy for AL amyloidosis: A case series and review of the literature. Am J Transplant. 2019 Nov; 19(11):3185-90.

47 Merlini G, Dispenzieri A, Sanchorawala V, Schönland SO, Palladini G, Hawkins PN, et al. Systemic immunoglobulin light chain amyloidosis. Nat Rev Dis Primers. 2018 Oct;4(1): 38.

48 Freeman R. Clinical practice. Neurogenic orthostatic hypotension. N Engl J Med. 2008 Feb;358(6):615-24.

49 Yam LT, Oropilla SB. Octreotide for diarrhea in amyloidosis. Ann Intern Med. 1991 Oct; 115(7):577.

50 Wixner J, Suhr OB, Anan I. Management of gastrointestinal complications in hereditary transthyretin amyloidosis: a single-center experience over 40 years. Expert Rev Gastroenterol Hepatol. 2018 Jan;12(1):73-81.

51 Rives S, Pera M, Rosiñol L, Vidal O, Miquel R, Solé M, et al. Primary systemic amyloidosis presenting as a colonic stricture: successful treatment with left hemicolectomy followed by autologous hematopoietic stem-cell transplantation: report of a case. Dis Colon Rectum. 2002 Sep;45(9):1263-6.

52 Park MA, Mueller PS, Kyle RA, Larson DR, Plevak MF, Gertz MA. Primary (AL) hepatic amyloidosis: clinical features and natural history in 98 patients. Medicine (Baltimore). 2003 Sep;82(5):291-8.

53 Oran B, Wright DG, Seldin DC, McAneny D, Skinner M, Sanchorawala V. Spontaneous rupture of the spleen in AL amyloidosis. Am J Hematol. 2003 Oct;74(2):131-5.
54 Berk JL, O’Regan A, Skinner M. Pulmonary and tracheobronchial amyloidosis. Semin Respir Crit Care Med. 2002 Apr;23(2):15565.

55 Baumgart JV, Stuhlmann-Laeisz C, Hegenbart U, Nattenmüller J, Schönland S, Krüger $\mathrm{S}$, et al. Local vs. systemic pulmonary amyloidosis-impact on diagnostics and clinical management. Virchows Arch. 2018 Nov;473(5): 627-37.

56 Fiorelli A, Accardo M, Galluccio G, Santini M. Tracheobronchial amyloidosis treated by endobronchial laser resection and self expanding Y stent. Arch Bronconeumol. 2013 Jul;49(7):303-5.

57 Kurrus JA, Hayes JK, Hoidal JR, Menendez MM, Elstad MR. Radiation therapy for tracheobronchial amyloidosis. Chest. 1998 Nov; 114(5):1489-92.

58 Vivino FB. Sjogren's syndrome: clinical aspects. Clin Immunol. 2017 Sep;182:48-54.

59 Thibault I, Vallières I. Macroglossia due to Systemic Amyloidosis: Is There a Role for Radiotherapy? Case Rep Oncol. 2011 May;4(2): 392-9.

60 Pau M, Reinbacher KE, Feichtinger M, Kärcher H. Surgical treatment of macroglossia caused by systemic primary amyloidosis. Int J Oral Maxillofac Surg. 2013 Feb;42(2):294-7.

61 Gadiwalla Y, Burnham R, Warfield A, Praveen P. Surgical management of macroglossia secondary to amyloidosis. BMJ Case Rep. 2016 Apr;2016:1136

62 Choufani EB, Sanchorawala V, Ernst T, Quillen K, Skinner M, Wright DG, et al. Acquired factor X deficiency in patients with amyloid light-chain amyloidosis: incidence, bleeding manifestations, and response to high-dose chemotherapy. Blood. 2001 Mar;97(6): $1885-7$.

63 Thompson CA, Kyle R, Gertz M, Heit J, Pruthi R, Pardanani A. Systemic AL amyloidosis with acquired factor X deficiency: A study of perioperative bleeding risk and treatment outcomes in 60 patients. Am J Hematol. 2010 Mar;85(3):171-3.

64 Elsaman AM, Radwan AR, Akmatov MK, Della Beffa C, Walker A, Mayer CT, et al. Amyloid arthropathy associated with multiple myeloma: a systematic analysis of 101 reported cases. Semin Arthritis Rheum. 2013 Dec; 43(3):405-12. 